\title{
Optical Fiber Spectroscopy for Food Quality and Safety Applications
}

\author{
Anna Grazia Mignani, Leonardo Ciaccheri, Andrea Azelio Mencaglia \\ CNR - Istituto di Fisica Applicata "Nello Carrara" \\ Via Madonna del Piano, 10 - 50019 Sesto Fiorentino (FI) - Italy \\ a.g.mignani@ifac.cnr.it
}

\begin{abstract}
A selection of fiber optic and micro-optic spectroscopy-based devices for food quality and safety applications is presented. Direct spectroscopy carried out in the visible and near-infrared bands provided a product fingerprints which were processed by means of multivariate analysis for predicting quality indicators. Chemically-mediated spectroscopy was used to implement sensors or dosimeters for quantifying analytes for food safety monitoring. The paper summarizes sensors designed and tested for application to the most common foodstuffs such as olive oil, milk and dairy products, fish, meat, as well as alcoholic beverages such as beer, wine, tequila, whisky, and many others.
\end{abstract}

Key words: micro-optics, fiber optics sensors, food, quality, safety, spectroscopy

\section{Food Quality and Safety Issues}

"Tell me what you eat, and I'll tell you who you are," is the famous statement by Savarin gastronome. Indeed, food is certainly a central and inseparable aspect of every historical period, every culture, every religion, and a topic of endless discussion. The food is not only nutrition, it is also a source of great enjoyment, and our health depends to a large extent on what we eat.

Roughly speaking, on a purely reductionist and scientific level, we need 2000 calories per day, with a typical intake of $40 \%$ carbohydrates, $30 \%$ proteins and $30 \%$ fats.

Within these basic needs, there are two aspects and properties of food:

- the hedonistic aspect: which tends to please our senses, not only the taste and the aroma, also other senses like the sight or the general impression we have from all senses - the hedonistic aspect is related to food quality;

- the health aspect: there are many functional and fortified foods, antioxidantrich vegetables and fruits that help you fighting disease, and slowing down the aging process, provided that the food is free of pathogens and toxins - the health aspect is related to safety.

Optical spectroscopy provides straightforward solutions to many requirements of quality and safety controls for the food and beverage industry [1, 2]. Two measurement approaches are possible:

Direct Spectroscopy, when the light intensity modulated through the analyte is measured. It is suitable for colorimetry, as well as for analyzing compounds with interfering spectra. In fact, the poor selectivity of optical spectroscopy in complex media can be overcome by means of multivariate data analysis and noise suppression algorithms.

Chemically-Mediated Spectroscopy, when the analyte under investigation interacts with a reagent and the status of the analyte is indirectly obtained by measuring the spectral properties of the reagent itself. A variety of sensors for food applications been presented that are based on chemically-assisted spectroscopy, since indicator chemistry has many chances to be adapted to give selectivity to a specific analyte [3].

This paper presents some examples of optical sensors making use of optical fibers and compact micro-optic components for food quality and safety monitoring. such as olive oil, milk and dairy products, fish, meat, as well as alcoholic beverages such as beer, wine, tequila, whisky, and many others.

\section{Direct Spectroscopy - Food Quality Assessment by VIS-NIR Fingerprints}

Direct spectroscopy is mainly used for food quality assessment. Since the sight is our primary sense providing us a first stimulus, 
reflectance spectroscopy, especially colorimetry, is an irreplaceable tool for food sorting along the entire production process. Colorimeters for manual inspection, as well as automatic food sorters making use of line-scan cameras or more sophisticated spectrometers, are commonly used to discard defected or offstandard products. Dry products such as pasta, biscuits, rice, seeds, beans, and soya are automatically sorted by means fast colorimeters, while fresh products like fruits or vegetables are sampled and checked by means of manual colorimeters [4]. Optical fiber devices are also used, since their geometrical versatility allows for localized monitoring even in harsh environment, for example in ovens to control the proper beef cooking [5].

Actually, also the near-infrared (NIR) spectrum up to $2500 \mathrm{~nm}$ provides valuable information. In fact, while the VIS spectrum reveals the presence of dyes and pigments, the NIR spectrum is informative for proteins, fats and carbohydrates, thanks to the presence of overtones and combinations of vibrational modes of $\mathrm{C}-\mathrm{H}, \mathrm{O}-\mathrm{H}$, and $\mathrm{N}-\mathrm{H}$ bonds $[6,7]$.

Relevant advantages of VIS-NIR optical spectroscopy can be summarized as follows:

- direct measurement of the food: no sample preparation is necessary; consequently, the analysis is simple, fast, it does not require manual intervention and can be carried out online in real time;

- a small quantity of sample is sufficient;

- compatibility for use in an industrial setting by means of low-cost instrumentation.

The chemical information contained in an absorption or reflectance spectrum is defined in the positions and intensities of the bands. Whereas the band positions give information about the appearance and the structure of certain chemical compounds in a mixture, the intensities of the bands are related to the yield of these compounds. Since most foodstuffs contain numerous compounds, the VIS-NIR absorption/reflectance spectra show broad peaks resulting from the convolution of the many overlapping signals. Indeed, this cumulative spectrum can be considered a sort of optical signature of the food, the univocal "fingerprint" from which to extract the analysis of several constituents, as well as the evaluation of quality indicators, or the authenticity of the product.

For qualitative and quantitative analysis, the spectroscopic fingerprinting must be calibrated against reference analytical data from a database of samples representing the best variability in the population. What is needed is a library of representative spectra and analytical data to which the spectrum of a test sample may be matched. After a data dimensionality reduction, in which a limited number of predictor variables is extracted from spectroscopic data, a "Calibration Matrix" is created from which the constituent of interest may be calculated by means of a linear combination of these predictors. The calibration equation has associated statistics which define the closeness of the fit of the actual and predicted values to the least square line. Then, a predicted-versusreference-plot is created to detect any aberrant data. Ideally, the scatter plot should contain data points distributed evenly along a straight line with a narrow confidence limit. A validation procedure is then applied for testing the effectiveness of calibration method. While the data dimensionality reduction is usually capable of identifying similarities among products, the correlation to quality indicators always needs the further steps of calibration and validation.

Given the nature and complexity of the spectroscopic and analytical data sets involved, many multivariate chemometric techniques have been proposed [ $8,9,10,11]$. The challenge of every multivariate data processing method is to provide excellent classification performance even when few training data are available.

Indeed, smart data processing makes VIS-NIR optical spectroscopy a rapid and nondestructive method for the multicomponent analysis of foodstuffs. Since water has a weak absorption in these spectral bands, also highmoisture foods can be easily analyzed.

VIS-NIR direct spectroscopy demonstrated effectiveness for many common foodstuffs, such as:

extra virgin olive oil: authentication of geographic origin of production, prediction of nutraceutic indicators, and fraud detection [12, 13, 14, 15];

- honey: authentication of geographic origin of production, prediction of nutraceutic indicators, and fraud detection [16, 17, 18];

tea: antioxidant capacity, soluble solid content, composition, and discrimination of varieties [19, 20, 21, 22];

- alcoholic beverages (beer, cognac, tequila, whisky): prediction of alcoholic content, and fraud detection [23, 24, 25, 26, 27];

dairy products: manufacturing processing, quality parameters, and identity $[28,29,30$, 31]. 


\section{Chemically-Mediated Spectroscopy for Food Safety Monitoring}

An indicator that changes the own optical properties interacting with an analyte is commonly called "optode" or "optrode" [32, 33, 34]: the monitoring of the target analyte is thus possible by measuring the analyte-induced modulation of the optical signal, typically absorption or fluorescence. The indicator must be physically immobilized inside a solid support, allowing optimized indicator-analyte interaction. Polymeric solid supports encapsulating indicators can be configured as little blocks or thin films suitable for coupling to fiber optic bundles or micro optic probes. The interrogating units associated to optrodes are similar to those used for direct spectroscopy measurements, typically making use of LEDs as sources and compact spectrometers or CCDs as detectors.

Although countless can be the biosensors for selective monitoring of a target analyte, the most modern instruments are made of sensing platforms for multianalyte detection by means of a single interrogating unit. These devices were successfully tested for toxin and bacteria monitoring, as well as for a more general food screening by using fluorescent transducers [35, $36,37]$.

\section{References}

[1] R.E. Wrolstad, T.E. Acree, E.A. Decker, M.H. Penner, D.S. Reid, S.J. Schwartz, C.F. Shoemaker, P. Sporns, Handbook of Food Analytical Chemistry, Pigments, Colorants, Flovours, Texture, and Bioactive Food Components, J. Wiley\&Sons, Hoboken NJ, 2005.

[2] J. Raty, K.E. Peiponen, T. Asakura, UV-Visible Reflection Spectroscopy of Liquids, Springer-Verlag, Berlin, 2004

[3]. O.S. Wolfbeis, Fiber Optic Chemical Sensors and Biosensors, Vols. I and II, CRC Press, Boca Raton FL, 1991.

[4] http://www.buhlergroup.com/17217IT.asp, http://www.zeiss.de/spectral

http://www.radixsystems.co.uk/index.htm, http://www.lotoriel.com/, http://www.konicaminolta.eu/.

[5] M. O'Farrell, E. Lewis, C. Flanagan, W.B. Lyons, N. Jackman, "Design of a system that uses optical-fiber sensors and neural networks to control a large-scale industrial oven by monitoring the food quality online", IEEE Sensors Journal, vol. 5, 2005, pp. 1407-1420.

[6] Y. Ozaki, W.F. McClure, A.A. Christy, Near Infrared Spectroscopy in Food Science and Technology, J. Wiley\&Sons, Hoboken NJ, 2007.

[7] B.G. Osborne, T. Fearn, P.T. Hindle, Practical NIR Spectroscopy with Applications in Food and Beverage Analysis, Longman Scientific \& Technical-Wiley, New York NJ, 1993.

[8] H. Mark, J. Workman Jr., Statistics in Spectroscopy, $2^{\text {nd }}$ ed., Academic Press, San Diego CA, 2003.

[ 9 ] H. Mark, J. Workman Jr., Chemometrics in Spectroscopy, Academic Press, London UK, 2007.
In addition to compact instruments for multianalysis, a particular attention was given to "safety spots" to be included in smart packaging. These spots were made of indicators which changed the color or fluorescence as a function of some deterioration inside the packaging, thus acting as a non-destructive testing system. For example, fish spoilage and other amine vapors were conveniently detected by means of colorimetric sensors [38, 39].

Since modified atmosphere using carbon dioxide or nitrogen is increasingly used for foodstuffs packaging, oxygen sensors to be used as visually-read or instrumentallyinterrogated patches were implemented for non-destructive testing of packaging integrity [40, 41, 42].

Indeed, odor sniffing of packaged food is a challenging idea, and many electronic noses based on optical technologies were proposed. They made use of non-selective sensors configured as arrays from which to extract an odor information. They are bio-inspired devices which convert the non-selective response of the sensor array into an odor pattern capable of providing a targeted olfactory perception [43, $44,45,46,47]$.

[ 10 ] R. Kramer, Chemometric Techniques for Quantitative Analysis, Marcel Dekker Inc., New York NJ, 1998.

[11] D. Toher, G. Downey, T.B. Murphy, "A comparison of model-based and regression classification techniques applied to near infrared spectroscopic data in food authentication studies", Chemometrics and Intelligent Laboratory Systems, vol. 89, 2007, pp. 102-115.

[12] G. Downey, P. Mclntyre, A.N. Davies, "Geographic classification of extra virgin olive oils from the Eastern Mediterranean by chemometric analysis of visible and near-infrared spectroscopic data", Applied Spectroscopy, vol. 57, 2003, pp. 158-163.

[13] M. Casale, P. Olivieri, C. Casolino, N. Sinelli, P. Zunin, C. Armanino, M. Forina, S. Lanteri, "Characterization of PDO olive oil Chianti Classico by non-selective (UV-visible, NIR and MIR spectroscopy) and selective (fatty acid composition) analytical techniques", Analytica Chimica Acta, vol. 712, 2012, pp. 56-63.

[14] N. Sinelli, L. Cerretani, V. Di Egidio, A. Bendini, E. Casiraghi, "Application of near (NIR) infrared and mid (MIR) infrared spectroscopy as a rapid tool to classify extra virgin olive oil on the basis of fruity attribute intensity", Food Reserach International, vol. 43, 2010, pp. 369-375.

[15] A.G. Mignani, L. Ciaccheri, H. Ottevaere, H. Thienpont, L. Conte, M. Marega, A. Cichelli, C. Attilio, A. Cimato, "Visible and near-infrared absorption spectroscopy by an integrating sphere and optical fibers for quantifying and discriminating the adulteration of extra virgin olive oil from Tuscany", Analytical \& Bioanalytical Chemistry, vol. 399, 2011, pp. 1315-1324. 
[16] T. Woodcock, G. Downey, C. O'Donnel, “Near infrered spectral fingerprinting for confirmation of claimed PDO provenance of honey", Food Chemistry, vol. 114, 2009, pp. 742-746.

[17] K. Ruoff, W. Luginbühl, S. Bogdanov, J.O. Bosset, B. Estermann, T. Ziolko, S. Kheradmandan, R. Amadò "Quantitative determination of physical and chemical measurands in honey by near-infrared spectrometry", European Food Research Technology, vol. 225, 2007, pp. $415-423$

[18] G. Downey, V. Fouratier, D. Kelly, "Detection of honey adulteration by addition of fructose and glucose using near infrared transflectance spectroscopy", Journal of Near Infrared Spectroscopy, vol. 11, 2003, pp. 447-456.

[19] M.H. Zhang, J. Luypaert, J.A. Fernández Pierna, Q.S. Xu, D.L. Massart, "Determination of total antioxidant capacity in green tea by near-infrared spectroscopy and multivariate calibration", Talanta, vol. 62,2004 , pp. 25-35

[20] X. Li, Y. He, C. Wu, D.W. Sun, "Non desctructive measurement and fingerprint analysis of soluble content of tea soft drink based on Vis/NIR spectroscopy", Journal of Food Engineering, vol. 82, 2007, pp. 316-323 [21] S.H. Yan, "Evaluation of the composition and sensory properties of tea using near infrared spectroscopy and principal component analysis", Journal of Near Infrared Spectroscopy, vol. 13, 2005, pp. 313-325.

[22] Y. He, X. Li, X. Deng, "Discrimination of varieties of tea using near infrared spectroscopy by principal component analysis and BP model", Journal of Food Engineering, vol. 79, 2007, pp. 1238-1242.

[23] V. Di Egidio, P. Oliveri, T. Woodcock, G. Downey, "Confirmation of brand identity in foods by near infrared transflectance spectroscopy using classification and class-modelling chemometric techniques - The example of a Belgian beer", Food Reasearch International, vol. 44, 2011, pp. 544-549.

[24] A. Nordon, A. Mills, R.T. Burn, F.M. Cusick, D. Littlejohn, "Comparison of non-invasive NIR and Raman spectrometries for determination of alcohol content of spirits", Analytica Chimica Acta, vol. 548, 2005, pp. 148158

[25] G.R. Jones, A.G. Deakin, R.J. Brookes, J.W. Spencer, "A portable liquor monitoring system using a PC-based chromatic technique", Measurement Science and Technology, vol. 20, 2009, pp. 75305-75312.

[ 26 ] O. Barbosa-García, G. Ramos-Ortíz, J.L. Maldonado, J.L. Pichardo-Molina, M.A. Meneses-Nava, J.E.A. Landgrave, J. Cervantes-Martínez, "UV-Vis absorption spectroscopy and multivariate analysis as a method to discriminate tequila", Spectrochimica Acta, vol. 66, 2007, pp. 129-134.

[27] W.M. MacKenzie, R.I. Aylott, "Analytical strategies to confirm Scotch whisky authenticity. Part II: mobile brand authentication", Analyst, vol. 129, 2004, pp. 607612.

[28] L. Čurda, O. Kukačková, "NIR spectroscopy: a useful tool for rapid monitoring of processed cheeses manufacture", Journal of Food Engineering, vol. 61, 2004, pp. 557-560.

[29] C.C. Fagan, M. Castillo, C.P. O'Donnel, D.J. Callaghan, F. A. Payne, "On.line prediction of cheese making indeces using backscatter of near infrared light", International Dairy Journal, vol. 18, 2008, pp. 120-128.

[30] R. Karoui, G. Mazerolles, E. Dufour, "Spectroscopic techniques coupled with chemometric tools for structure and texture determinations in dairy products", International Dairy Journals, vol. 13, 2003, pp. 607-620.
[31] R. Karoui, J. De Baerdemaeker, "A review of the analytical methods coupled with chemometric tools for the determination of the quality and identity of dairy products", Food Chemistry, vol. 102, 2007, pp. 621-640. [32] O.S. Wolfbeis, "Fiber-optic chemical sensors and biosensors", Analytical Chemistry, vol. 76, 2004, pp. 3269-3284.

[33] O.S. Wolfbeis, "Fiber-optic chemical sensors and biosensors", Analytical Chemistry, vol. 78, 2006, pp. 3859-3874.

[34] O.S. Wolfbeis, "Fiber-optic chemical sensors and biosensors", Analytical Chemistry, vol. 80, 2008, pp. 4269-4283.

[35] F.S. Liegler, C.R. Taitt, L.C. Shriver-Lake, K. E. Sapsford, Y. Shubin, J.P. Golden, "Array biosensor for detection of toxins", Analytical and Bioanalytical Chemistry, vol. 377, 2003, pp. 469-477.

[ 36 ] C.C. Jung, E.W. Saaski, D.A. McCrae, B.M. Lingerfelt, G.P. Anderson, "RAPTOR: a fluoroimmunoassay-based fiber optic sensor for detection of biological threats", IEEE Sensors Journal, vol. 3, 2003, pp. 352-360.

[ 37 ] S.Raza, M.G.E.G. Bremera, M. Giesbers, W. Nordeb, "Development of a biosensor microarray towards food screening using imaging surface plasmon resonance", Biosensors \& Bioelectronics, vol. 24, 2008, pp. 552-557.

[38] A. Pacquit, J. Frisby, D. Diamond, K.T. Lau, A. Farrell, B. Quilty, D. Diamond, "Development of a smart packaging for the monitoring of fish spoilage", Food Chemistry, vol. 102, 466-470

[39] K.I. Oberg, R. Hodyss, J.L. Beauchamp, "Simple optical sensor for amine vapors based on dyed silica microspheres", Sensors and Actuators B, vol. 115, 2006, pp. 79-85.

[40] A. Mills, "Oxygen indicators and intelligent links for packaging food", Chemical Society Reviews, vol. 34, 2005, pp. 1003-1011.

[41] F.C. O'Mahony, T.C. O'Riordan, N. Papkovskaia, J.P. Kerry, D.B. Papkovsky, "Non-destructive assessment of oxygen levels in industrial modified atmosphere packaged cheddar cheese", Food Control, vol. 17, 2006, pp. 286-292.

[42] http://www.oceanoptics.com/products/Redeye.asp . [43] M.C. Janzen, J.B. Ponder, D. P. Bailey, C.K. Ingison, K.S. Suslick, "Colorimetric sensor arrays for volatile organic compounds", Analytical Chemistry, vol. 78, 2006, pp. 3591-3600.

[44] X. Huang, J. Xin, J. Zhao, "A novel technique for rapid evaluation of fish freshness using colorimetric sensor array", Journal of Food Engineering, vol. 105, 2011, 632-637.

[45] C. Di Natale, E. Martinelli, R. Paolesse, A. D’Amico, D. Filippini, I. Lundström, "An experimental biomimetic platform for artificial olfaction", PloS ONE (www.plosone.org), vol. 3, 2008, e3139.

[46] R. Paolesse, L. Lvova, S. Nardis, C. Di Natale, A. D'Amico, F. Lo Castro, "Chemical images by porphyrin arrays of sensors", Microchimica Acta, vol. 163, 2008, pp. 103-112.

[47] J.C. Jokerst, J.A. Adkins, B. Bisha, M.M. Mentele, L.D. Goodridge, C.S. Henry, "Development of a paperbased analytical device for colorimetric detection of select foodborne pathogens", Analytical Chemistry, vol. 84, 2012, pp. 2900-2907. 